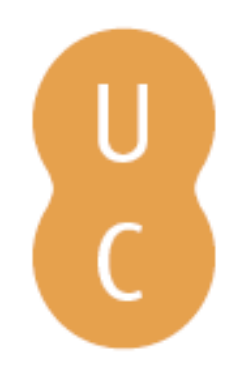

\title{
nommalina
}

\section{O acervo documental do arquivo da Universidade de Coimbra representado na BiblioAlimentaria}

\author{
Autor(es): $\quad$ Bandeira, Ana Maria Leitão \\ Publicado por: Imprensa da Universidade de Coimbra \\ URL \\ persistente: URI:http://hdl.handle.net/10316.2/43686 \\ DOI: $\quad$ DOI:https://doi.org/10.14195/978-989-26-1364-2_1 \\ Accessed : $\quad$ 26-Apr-2023 06:54:17
}

A navegação consulta e descarregamento dos títulos inseridos nas Bibliotecas Digitais UC Digitalis, UC Pombalina e UC Impactum, pressupõem a aceitação plena e sem reservas dos Termos e Condições de Uso destas Bibliotecas Digitais, disponíveis em https://digitalis.uc.pt/pt-pt/termos.

Conforme exposto nos referidos Termos e Condições de Uso, o descarregamento de títulos de acesso restrito requer uma licença válida de autorização devendo o utilizador aceder ao(s) documento(s) a partir de um endereço de IP da instituição detentora da supramencionada licença.

Ao utilizador é apenas permitido o descarregamento para uso pessoal, pelo que o emprego do(s) título(s) descarregado(s) para outro fim, designadamente comercial, carece de autorização do respetivo autor ou editor da obra.

Na medida em que todas as obras da UC Digitalis se encontram protegidas pelo Código do Direito de Autor e Direitos Conexos e demais legislação aplicável, toda a cópia, parcial ou total, deste documento, nos casos em que é legalmente admitida, deverá conter ou fazer-se acompanhar por este aviso.

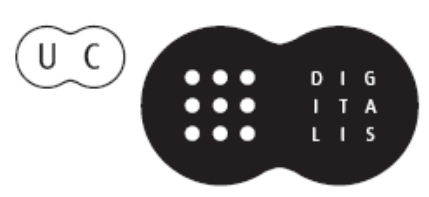




\section{BIBLIOALIMENTARIA}

Alimentação, Saúde e Sociabilidade à Mesa no acervo bibliográfico da Universidade de Coimbra

Carmen Soares (Coord.)
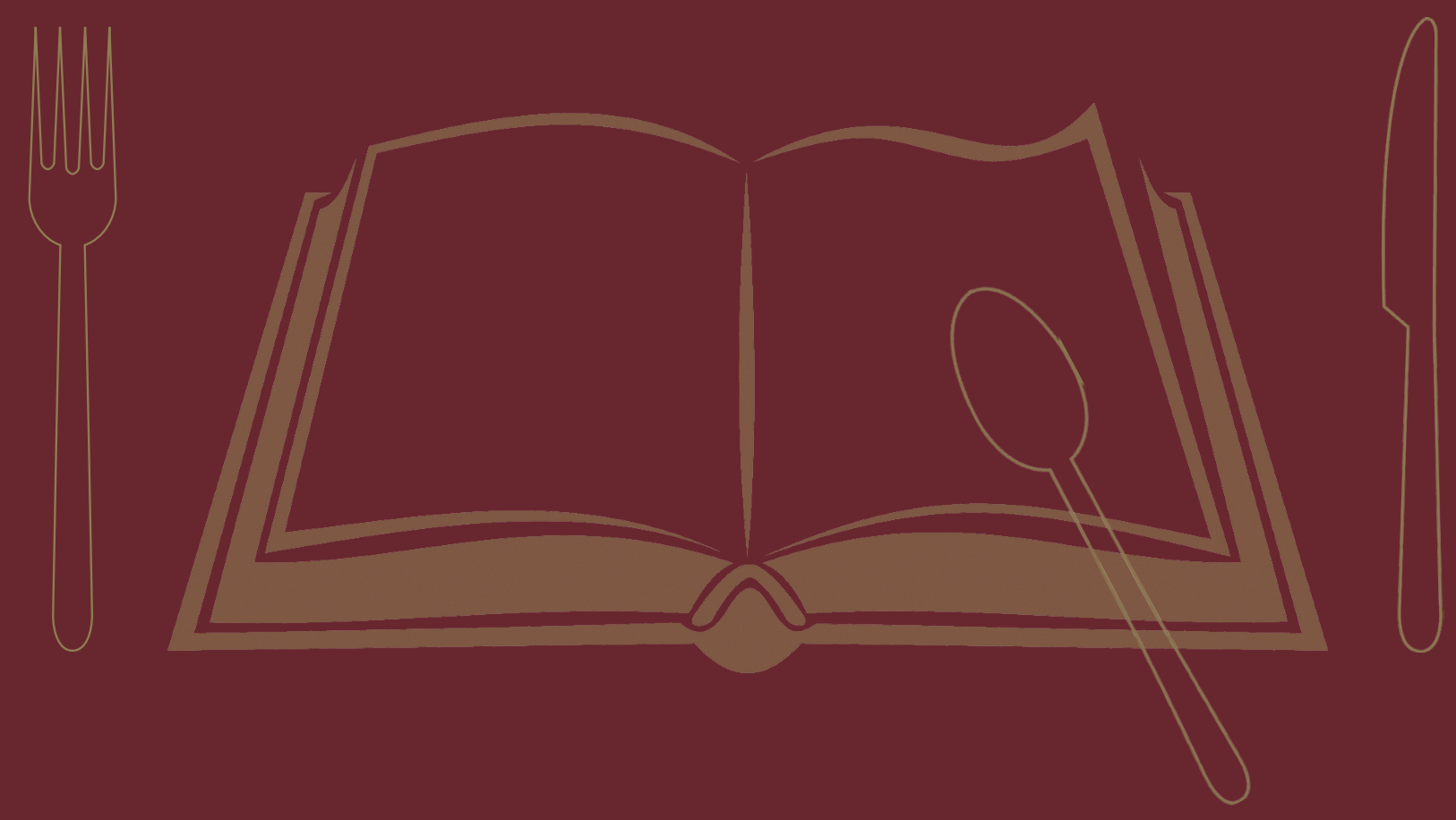

Imprensa da Universidade de Coimbra

Coimbra University Press 
O acervo documental do

\section{Arquivo da Universidade de \\ Coimbra representado na}

\section{BiblioAlimentaria}

Ana Maria Leitão Bandeira

A dinamização, divulgação e valorização do acervo bibliográfico da Universidade de Coimbra, no domínio da alimentação, levada a cabo com a exposição bibliográfica BiblioAlimentaria, conta com a participação do Arquivo da Universidade de Coimbra (AUC). Entre o seu riquíssimo acervo, são inúmeros os testemunhos documentais que ilustram aquilo que é o património alimentar português, nas suas mais diversas vertentes.

O Guia de Fundos do Arquivo da Universidade de Coimbra, publicado em 2015, permite conhecer 526 fundos arquivísticos e coleções aqui existentes, provenientes das mais diversas instituições. ${ }^{93}$ Este acervo reúne um conjunto de fontes documentais primárias, muitas vezes desconhecidas, que veem agora a ocasião de serem divulgadas.

Foi no seio de alguns destes fundos documentais que foi feita a pesquisa que permitiu identificar as peças expostas, ilustrativas das mais variadas situações, seja quanto à memória gastronómica, aos registos de contabilidade e administração, às atividades de agricultura, comércio e indústria alimentar, ao alimento enquanto medicamento, à dieta alimentar, à preocupação de alimentação equilibrada no refeitório universitário, ou mesmo às manifestações de sociabilidade e etiqueta, na degustação de alimentos.

É assim que pode trazer-se à colação a produção agrícola, ilustrada com o pagamento de foros e rendas. Ao escolher o Livro donde se escrevem as pagas dos carretos das rendas que se recolbem per mordomos: deste anno que começou o $1 .^{\circ}$ de julbo $1616 \mathrm{em}$ que foi

93 Pode ser consultado na sua versão digital, acessível através da página institucional do AUC ou em http://www.uc.pt/imprensa_uc/catalogo/documentos/ GuiaFundosAUC celeireiro o Sor. João Rodrigues Banha e escrivão o Sor. João de Villas Boas conegos, pertencente ao Cabido da Sé de Coimbra, puderam ilustrar-se os pagamentos em milho, cevada, centeio e cebolas, mais concretamente, a quantidade de carros de cebolas (cat. n. ${ }^{\circ} 42$ ), e também as réstias e braços de cebolas. O citado livro inclui dados até 1618 e são desse ano os registos da entrega de cebolas, provenientes dos lugares de Avenal, Cardal e Rodam (c. Condeixa-a-Nova), entregues nos meses de agosto e setembro. O tema do pagamento de rendas poderia, só por si, dar lugar a uma exposição, tal é a diversidade de fontes documentais, seja através de livros de escrituras de arrendamento e emprazamento, registos de receita de foros e rendas ou róis de foreiros e rendeiros, provenientes de instituições monásticas de Coimbra, como o Mosteiro de Santa Cruz, Mosteiro de Celas, Mosteiro de Santa Clara, Mosteiro de São Jorge, etc., ou instituições como o Hospital Real de Coimbra, o Hospital de São Lázaro, a Mitra Episcopal de Coimbra, as igrejas colegiadas de Santa Justa, São Bartolomeu, São João de Almedina, e tantas outras, incluindo a própria Universidade (que possuiu um vasto património rústico e urbano, extinto pelo Decreto de 5 de maio de 1835, que ordenou a incorporação da "Fazenda da Universidade" nos Bens Próprios Nacionais). ${ }^{94}$

A memória gastronómica, no que toca a alimentos adquiridos pela comunidade estudantil e funcionários da Universidade de Coimbra, pode ser ilustrada com os géneros vendidos na designada feira dos estudantes que era considerada uma feira franca. A existência desta feira, localizada, inicialmente, na praça de Almedina, antes de ser transferida para a alta de Coimbra, pode ser conhecida pela leitura de diversa legislação régia enviada à Universidade (Alvarás, Cartas e Provisões) desde o século Xvi. Os próprios Estatutos da Universidade de Coimbra, como, por exemplo, os de 1559, contêm informação sobre a sua existência. ${ }^{95}$ Também os Estatutos de 1653 contêm determinações sobre o seu funcionamento, os almotacés que a governavam (e por isso possuíam o direito de

94 Vd. Brandão, Mário; Almeida, Manuel Lopes de (1937), A Universidade de Coimbra: esboço da sua bistória. Coimbra, p. 128.

95 Vd. Estatutos da Universidade de Coimbra (1559). Com introdução e notas bistóricas e críticas de Serafim Leite. Coimbra, 1963, pp. 149-151, 178-179, 197. 
usar uma vara vermelha, à semelhança dos almotacés da Câmara de Coimbra), os direitos e deveres dos vendedores, dos "regatões e regateiras", existindo mesmo um Regimento da feira. ${ }^{96}$

Ainda hoje, o Largo da Feira, frente à Sé Nova de Coimbra, evoca a "feira dos estudantes", semanal, que ali decorria, e a celebrar a sua existência foi selecionado, entre o acervo documental do AUC, o livro que apresenta o seguinte termo de abertura: Livro de registo dos preços porque em cada huma das feiras forem almotaçados todos os géneros que a ella vierem, de 1796 a 1809 (cat. n 47). Este livro tem ainda um rótulo de título que o identifica como Diário dos preços porque são Almotaçados os Géneros de todas as qualidades que vem à Feira... e apresenta os produtos vendidos e a diversidade de preços, ao longo dos meses de cada ano. Entre a variedade de alimentos situam-se os peixes: cação, ruivo, pescada, chicharro, dourada, congro, rodovalho, raia, sardinha (fresca e salgada, referidas também como "frescal" e "amarela") e os crustáceos, como os caranguejos e os camarões. Quanto a legumes: o repolho, o feijão (o “da terra”, o "carrapato" e o "frade”); entre as frutas, cite-se a cereja, a ameixa, a uva, etc. Podem conhecer-se, ainda, alguns outros produtos, como: a chouriça, o presunto, o "toucinho do Alentejo" e o "queijo do Alentejo".

Foi recolhido no fundo documental da Universidade, na série de documentos da Mesa da Fazenda (ou "contas”), um curioso e raro documento que não podia deixar de figurar na exposição. Trata-se do registo de despesa com a oferta das designadas propinas dos doces (cat. no 43), feita em 1629 pela Universidade de Coimbra ao Conselho Supremo da Corte em Madrid, durante o reinado de D. Filipe II, sendo reitor da Universidade D. Francisco de Brito de Meneses. A despesa referida diz, apenas, respeito ao transporte dos doces, com indicação dos dias gastos por Agostinho Dias, caminheiro da Universidade, para se deslocar a Madrid.

96 Vd. a edição fac-similada Estatutos da Universidade de Coimbra (1655). Coimbra: Acta Universitatis Conimbrigensis, 1987, pp. 82-83, 90-91, 101. Também Fonseca, Fernando Taveira da (1995), A Universidade de Coimbra (1700-1771). Coimbra: Acta Universitatis Conimbrigensis. Septingentesimo Natali Edita, pp. 348-349, 351-353 , analisa a existência desta feira e seu funcionamento.

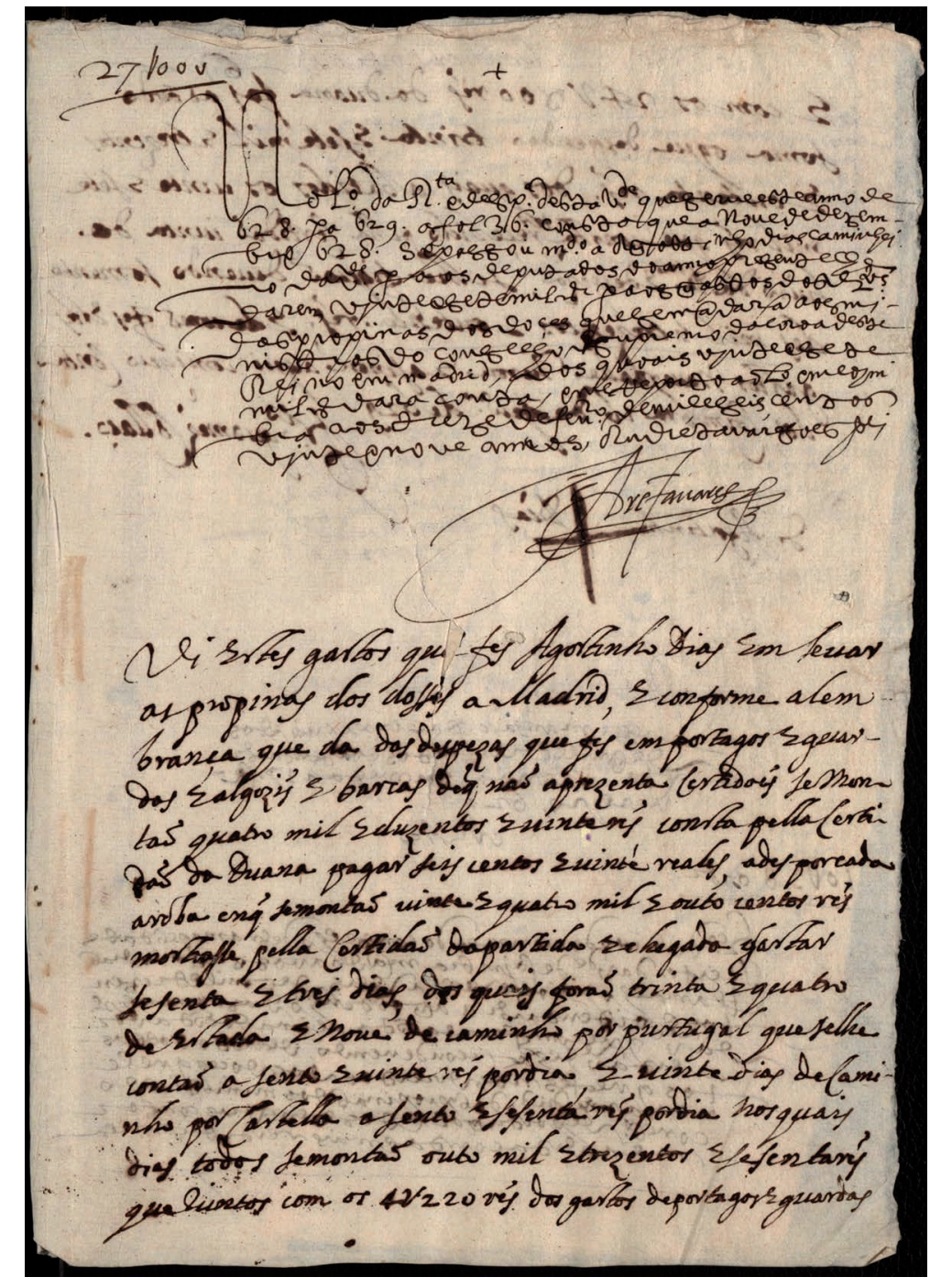

Esta tradição da oferta de doces, certamente que teve manifestação ao longo do tempo, sendo os doces conventuais confecionados em casas monásticas de Coimbra, como atestam os exemplos do pagamento feito pela Universidade de Coimbra a D. Maria Manuel, religiosa do Mosteiro de Celas, em junho de $1628 .^{97}$

97 Vd. Universidade de Coimbra (F); Livros de receita e despesa (SR); Livro da receita e despesa da Universidade de Coimbra, 1627-1628, fl. 89 - cota AUC-IV-1. ${ }^{2}$ E-12-3-7. Referências a pagamentos semelhantes, para outras datas, figuram em documentação já publicada por Almeida, Manuel Lopes de (1972), Artes e ofícios em documentos da Universidade, vol. 3 (1630-1650). Coimbra, p. 10. 
O Real Colégio de São Pedro é um dos colégios universitários evocados nesta exposição, através do Livro da superintendência da cozinba, de 1594-1595 (cat. n. ${ }^{\circ}$ 41). A série documental formada por esta tipologia de livros é de excecional riqueza, pela diversidade de informações sobre os hábitos alimentares (o que se adquiria diariamente para consumo no colégio) e por ilustrar um grande período cronológico, pois estão recenseados 70 livros, desde 1587 a 1834. O livro apresentado dá a conhecer os alimentos adquiridos: perdizes, pescada, ovos, "hum cambo de linguado", vaca, couves, manteiga, etc., e também as ervas aromáticas e especiarias com que se temperavam os alimentos: "de adubos seis reis", "de mostarda dous reis", "de cheiros três reis", "de coentros", "de borragens e outras mezinhas", etc. Ficaram, ainda, esporadicamente, registados alguns utensílios adquiridos para a cozinha: "de huma panela e huma tigela", "de hum alguidar" e outros pequenos gastos, como os pagamentos ao "moço que trouxe as castanhas", ao "moço que trouxe o peixe", "de amanhar huma machadinha", a compra de "dous púcaros de vidro", etc.

A confeção dos alimentos exigia os aprestos necessários a uma cozinha, que podem ser conhecidos quando se lê, por exemplo, um outro livro selecionado, o Livro de inventários do refeitório, $\partial a$ cozinha e da capela do Real Colégio de São Paulo, 1778-1807 (cat. $\mathrm{n}^{\circ} 46$ ). Periodicamente, quando se verificava a eleição do novo reitor do colégio, e também do superintendente da cozinha e do refeitório, fazia-se um balanço do que existia e esta é a forma de perpetuar o conhecimento de quais eram os utensílios do refeitório e da cozinha: toalhas, guardanapos, talheres, garrafas, bacias, açafates, copos e galhetas do refeitório; ou as marmitas, torteiras, estufadeiras, frigideiras, caçarolas, tachos, cafeteiras, formas de pastéis, caldeirões, almotolias, almofarizes, escumadeiras, passadores, funis, púcaros, raladores e tantos outros utensílios da cozinha.

No seio do acervo documental deste colégio existem outros tantos livros que poderiam ser trazidos à colação, como, por exemplo: Livros de despesa com pão, também conhecidos como Livros da padeira ou ainda os "Livros dos pães" onde se regista o consumo do pão, seja na forma de trigo cozido (em pães, ou mesmo em biscoitos), seja na utilização do pão em "sopas de carangueja”, "sopas douradas", "sopas de leite crespo", "fatias de ovos" e "fatias de leite", como é comum serem referidas, nos registos lançados nesses mesmos livros, existentes de 1703 a 1739.98

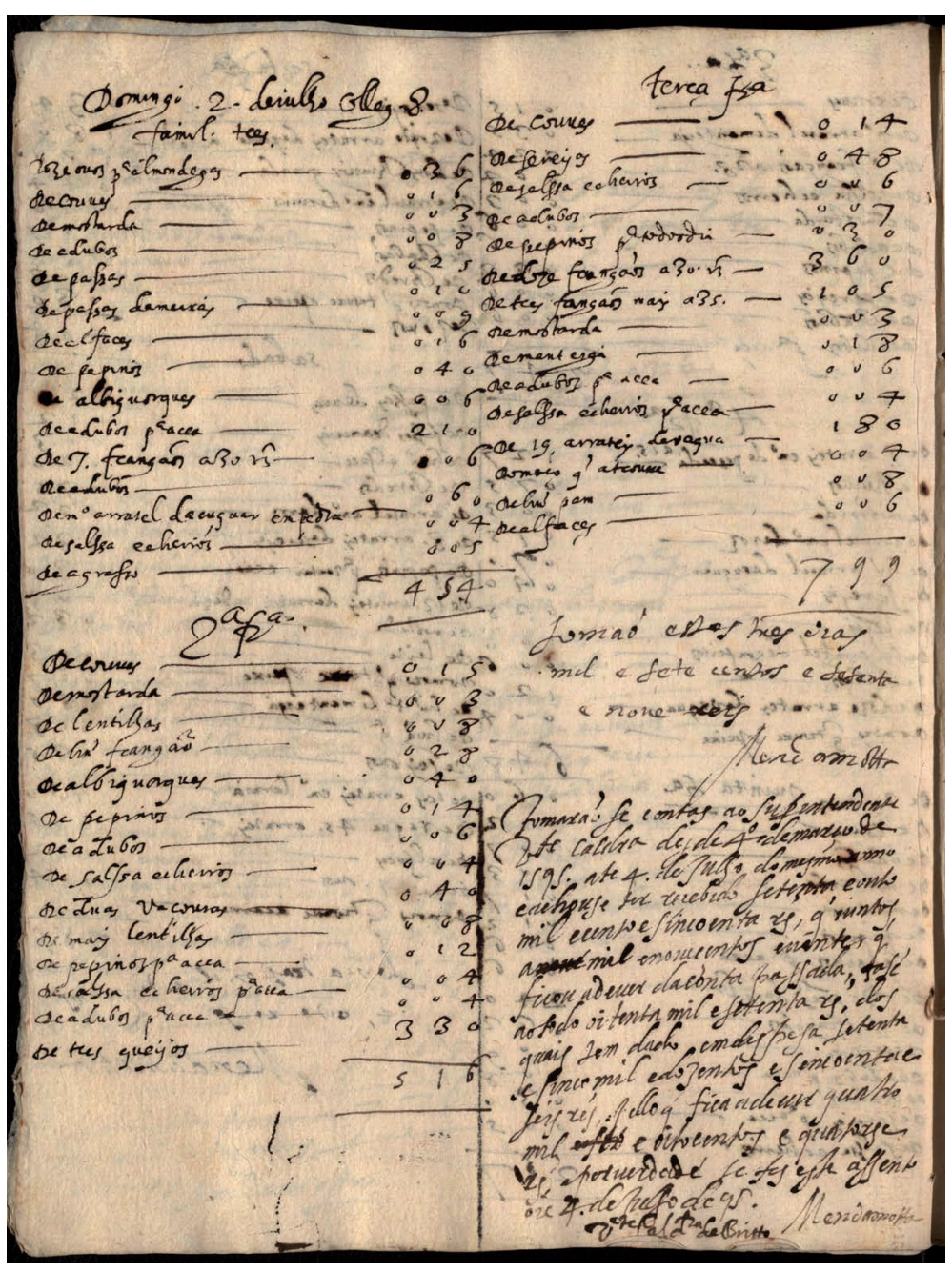

98 Um estudo sobre o acervo documental deste Colégio e sua descrição arquivística foi já publicado por Bandeira, Ana Maria Leitão; Costa, Anabela Rodrigues Oliveira (2014), O Real Colégio de São Paulo: acervo documental de um colégio universitário de Coimbra (1559-1834). Boletim do Arquivo da Universidade de Coimbra 27: 7-59, acessível em http://impactum-journals.uc.pt/index.php/boletimauc/article/ view/1784. As informações sobre hábitos alimentares figuram, particularmente, nas p. 37-42, quando se descrevem as séries documentais de Livros de despesa com pão e Livros de despesa da superintendência da cozinha. 


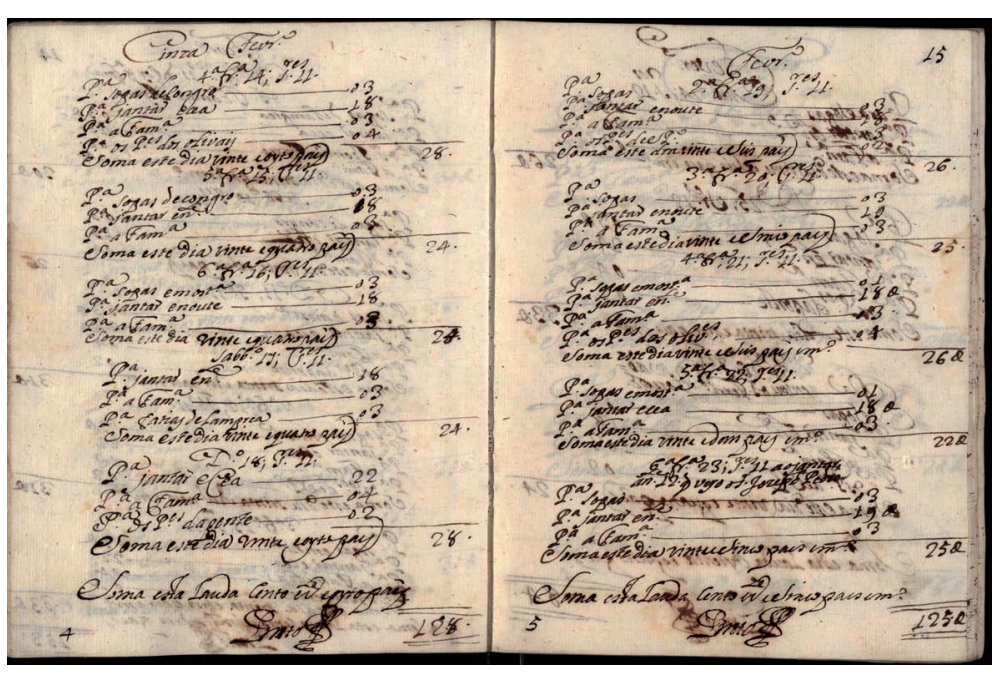

Os inventários judiciais são uma fonte inquestionável, para conhecer o recheio das habitações, os bens móveis e, concretamente, os utensílios de uso doméstico, na cozinha e na sala de refeições. O Arquivo da Universidade é simultaneamente Arquivo Distrital de Coimbra e, por esta razão, possui no seu acervo os fundos documentais de tribunais das comarcas deste distrito, sendo inúmeros os exemplos de inventários judiciais que poderiam ter sido apresentados.

No entanto, foi escolhido um outro inventário judicial, proveniente do fundo documental do Colégio de Jesus de Coimbra (cat. n. ${ }^{\circ 4}$ ). Trata-se de um traslado, em pública forma, do inventário de bens, datado de 1631, elaborado por óbito do doutor Francisco da Fonseca, instituidor da Capela de São Francisco Xavier, situada no Colégio de Jesus de Coimbra. Revela todos os seus bens de raiz que reverteram, na sua maioria, para o referido Colégio, e bens particulares de sua casa. Destaquem-se, neste inventário, as referências a prataria: saleiro, pimenteiro, gomil, colheres, pichel, etc., bem como a lousa e couzas de cozinba, em que se incluem as porcelanas da Índia e, ainda, caldeiras, tachos, bacias, pratos, jarro e pichel de estanho, escumadeira, etc.

Quando o Governo Civil de Coimbra foi criado, na sequência da reforma administrativa determinada com a Carta de lei de 25 de abril de 1835, à semelhança do que se passou em todos os distritos do país, o governador civil recebeu, entre outras atribuições, as de inspeção, licenciamento e coordenação das atividades económicas. Desta forma, a documentação emanada é um riquíssimo repositório para o conhecimento de atividades de comércio e indústrias de transformação alimentar. É por esta razão que são inúmeros os processos de licenciamento de fábricas de massas alimentícias, destilarias, fábricas de refinação de açúcar, de moagens, etc. Neste acervo, foram escolhidos apenas dois processos de licenciamento, por questões de gestão de espaço expositivo: primeiramente o processo, datado de 1896, para licenciamento de uma fábrica de massas alimentícias e moagem (cat. n. ${ }^{\circ}$ 90), que laboraria com motor a vapor, localizada no Porto dos Bentos, junto à estrada da Beira, na freguesia da Sé Velha, em Coimbra, sendo seu proprietário a firma Dias Pereira Marques Pinto \& Companhia (só foi feita aprovação do seu funcionamento, depois de uma visita sanitária); em segundo lugar - no ano de 1901, a fábrica de refinação de açúcar, situada no Largo da Sota, em Coimbra, de Carlos Alberto de Oliveira Fernandes (cat. n. ${ }^{\circ}$ 91). De acordo com esta documentação, seguindo a legislação em vigor, como o decreto de 21 de outubro de 1863 (de acordo com este decreto, a fábrica era considerada um estabelecimento de segunda classe, indicando-se, como inconvenientes da sua existência, o fumo, o mau cheiro e perigo de incêndio), pretendia-se que as condições higiénicas de laboração fossem aprovadas, depois de uma visita sanitária, efetuada pelo delegado de saúde. Toma-se conhecimento, com a leitura destes documentos, que o sistema de fabrico se limitava "a clarificar ou refinar o açúcar" em rama, por meio da sua liquidificação, em tachos de cobre.

O acervo documental do Governo Civil é fértil em exemplos que dizem respeito ao licenciamento de locais de comércio e confeção de alimentos: restaurantes, casas de pasto, cafés, tabernas, etc. De entre os designados Livros de licenças de porta aberta (onde se regista a data de licença, período de funcionamento do estabelecimento, nome do proprietário e local onde se situava) foi selecionado um volume, de 1913-1915, para ilustrar esta riquíssima informação (cat. n. ${ }^{\circ}$ 92). O referido volume permite-nos identificar, por exemplo: a taberna de Maria Benedita das Neves, na Rua Nova; o "café com seu bilhar" de Lúcio Augusto de Figueiredo, na Rua 
Francisco Ferrer; a taberna de Luís Barros de Oliveira, também na Rua Nova; o "Restaurant" de Manuel Ferreira da Silva, na Rua da Sofia; a "casa de pasto" de Joaquina Cardoso, no Largo do Paço do Conde; o "café com bilhares" na Rua Visconde da Luz, de J. M. Abrantes; o "Restaurant" denominado "Cozinha Moderna”, na Rua do Cosme, de Francisco Batista e Comp. ${ }^{a}$; o "botequim" de Jorge Rodrigues de Moura, na Rua Joaquim António de Aguiar, e tantos outros que traduzem a multiplicidade de ofertas que a cidade proporcionava.

A revolução industrial do século xix irá estimular uma alteração de hábitos alimentares, ao permitir o acesso rápido e generalizado a certos alimentos, como já foi referido com alguns exemplos: produção industrial de massas alimentícias e refinação de açúcar, em estabelecimentos situados na cidade de Coimbra.

Mas o progresso industrial irá refletir-se, também, em inovações que alterarão definitivamente a forma de conservação de alimentos, como foi a invenção dos sistemas de refrigeração e congelação. Os irmãos franceses Ferdinand-Philippe Carré e Edmond-Edouard Carré rivalizaram, no século XIX, com outros inventores de equipamento de refrigeração e fabrico de gelo. É da autoria do primeiro a invenção do aparelho apresentado na Exposição Universal de Londres, em 1862.99 Terá sido este, ou um outro já mais aperfeiçoado, o que foi adquirido para o Gabinete de Física da Faculdade de Filosofia, em 1870, através do doutor António dos Santos Viegas. De acordo com o recibo de pagamento que se apresenta e que terá sido assinado por Edmond Carré (figura apenas, como assinatura, E. Carré) este equipamento de Production du froid et de la glace, nouveaux appareils. Appareils spécieaux pour cabinets de phsysique et laboratoires - foi adquirido em Paris, em agosto de 1870 e foi pago em 30 de junho de 1871 (cat. n. $\left.{ }^{\circ} 89\right) .{ }^{100}$

99 Vd. Larousse, Pierre (1877), Grand Dictionnaire Universel. tome 13 (1.er supplement), Paris, p. 468.

100 Uma cópia do recibo de pagamento encontra-se inserida no processo que contem a Relação dos documentos de despeza feita nos diversos estabelecimentos e repartiçães abaixo designados, pela ordem de pagamento n. 189 de 1869 a 1870 (Universidade de Coimbra (F); Documentos de despesa (SR); 1871 (janeiro-junho) - AUC - II-1. $\left.{ }^{a} \mathrm{D}-7-3-23\right)$. O seu original deve conservar-se no Arquivo Nacional da Torre
Como o documento textualmente refere, foi especialmente concebido para gabinetes de física e laboratórios, mas abriria campo a uma multitude de aplicações médicas e farmacêuticas e também rasgaria caminho para uma profunda alteração no sistema de conservação e refrigeração de alimentos.

A preocupação, por parte da Universidade de Coimbra, com uma alimentação adequada para os alunos universitários, pode ser ilustrada, para período bem mais recente, através de um outro documento bem apelativo. Trata-se do plano de atividades para o ano letivo de 1971-1972 (cat. n. ${ }^{\circ}$ 81), proposto pelo Dr. António Luzio Vaz, então "gerente" do Refeitório da Universidade de Coimbra, onde eram servidas refeições em sistema de "self-service”. Neste documento fica bem explícita a preocupação de uma racionalização das refeições, a eliminação de pratos que pelas suas qualidades eram desprovidos de valor nutritivo, a introdução do pão integral e de pratos de peixe fresco, as refeições guarnecidas com saladas, etc., sendo estas apenas algumas das medidas que revelam o cuidado em obter "uma alimentação equilibrada para um completo rendimento escolar" como refere o autor do plano referido.

O elenco, de peças arquivísticas apresentadas, termina com a inclusão de ementas de refeições, retratando a sociabilidade, no convívio que tem por mote a reunião e celebração, em almoços e jantares de comemoração. A composição e número dos pratos servidos, a ordem de sua degustação, a terminologia adotada, uma descrição mais sucinta ou alargada da gastronomia, a inclusão de antepasto, a descrição de doces, de vinhos, licores, etc., são alguns dos temas que podem ser estudados nesta documentação efémera. Desta forma, e com esse intuito, foram identificados e selecionados: o menu do jantar oferecido pela Associação Comercial Chinesa em Macau ao comandante e oficiais do navio Gonçalves Zarco, em 13 de março de 1935 (cat. n. ${ }^{\circ}$ 98) e a ementa do almoço de homenagem ao Presidente da República general Óscar Carmona, em 5 de agosto de 1938, em Angola (cat. n. ${ }^{\circ}$ 99).

do Tombo, no fundo documental do Ministério do Reino, à semelhança do que se passa com outros exemplos de recibos de pagamentos de despesas da Universidade de Coimbra. 
Estas peças documentais foram recolhidas no espólio de um arquivo pessoal existente no AUC. Trata-se do arquivo de João Jardim de Vilhena (1873-1966), que doou à Universidade de Coimbra grande parte da sua correspondência pessoal e, sobretudo, um conjunto considerável de manuscritos, iconografia e folhetos impressos que foi reunindo ao longo da sua vida, nos quais se inclui um interessante conjunto destes cardápios, alguns deles ainda manuscritos. A designação de ementa ou de menu é utilizada indistintamente, em pequenos folhetos ou em cartões divulgativos, encontrando-se muitos deles assinados por participantes dos encontros. ${ }^{101}$ No caso da ementa de Macau, está impressa em português e também com carateres chineses e revela uma partilha de gastronomia oriental e ocidental, ao conjugar sopa de barbatana de tubarão, ninhos de salangana e ovos de pomba, juntamente com filetes de garoupa, galinha corada com presunto, etc.

Os menus ou ementas (ou ainda cardápios) foram, nos últimos anos, objeto de estudo, no Brasil, em interessantes e inovadores trabalhos de investigação, num reconhecimento da importância deste património documental para a memória gastronómica e, também sem ser apenas numa perspetiva gastronómica, podendo ser interpretados com uma leitura crítica, quanto ao seu grafismo, banquetes ou homenagens para os quais foram elaborados, locais de reunião, etc. Podem referir-se aqui as coleções de menus que foram objeto desses estudos: a que foi reunida pelo Imperador do Brasil D. Pedro II, e que foi oferecida à Biblioteca Nacional do Rio de Janeiro ${ }^{102}$, ou ainda a coleção agrupada pelo poeta e jornalista Olavo Bilac e hoje localizada na Academia Brasileira de Letras, da qual foi fundador. ${ }^{103}$

101 Refira-se o trabalho de investigação que teve por objeto o estudo de menus ou ementas: Braga, Isabel Drumond (2006), Menus em Portugal: para uma bistória das artes de servir à mesa. Lisboa: Chaves Ferreira.

102 Que serviram de tema ao trabalho de Boccato, André; Lellis, Francisco (2013), Os Banqueted do Imperador. São Paulo: Ed. Senac.

103 Parte desta coleção é divulgada no trabalho de Garcia, Lúcia (2011), Para uma bistória da belle-époque - a coleção de cardápios de Olavo Bilac. São Paulo, Imprensa Oficial.

\section{Mais de um século em prol}

\section{da agricultura: a Gazeta Jas Aldeias}

Maria Helena da Cruz Coelbo

Será uma verdade elementar afirmar que, antes de consumir, é preciso produzir. Logo, no que diz respeito à alimentação, diríamos que, antes de comer, é preciso semear, plantar, colher, se pensamos no pão, no vinho, nos legumes, nos produtos hortícolas, na fruta; criar e cuidar, se pensamos nos animais domésticos; capturar e recolher se pensamos na caça e na recoleção da cera e do mel; pescar no mar e nos rios, se pensamos no peixe; trabalhar nas marinhas, se pensamos no sal. Ao que poderíamos acrescentar todo um leque de tarefas nos moinhos, nos lagares de vinho ou azeite, na confeção e conservação dos produtos alimentares, para só nos atermos às atividades mais básicas.

Assim, porque o homem para subsistir se teve de nutrir, necessário foi que caçasse, recolhesse ou agricultasse. E, desde que aprendeu a trabalhar a terra, foi-se continuamente esforçando por colher mais e melhores frutos.

A agricultura, que surgiu no Crescente Fértil há muitos milhares de anos, em conjugação com a sedentarização das populações e a domesticação dos animais, foi porém evoluindo muito lentamente no contexto de uma longuíssima duração. Houve de facto mudanças na adaptação de diferentes sementes e plantas, nas técnicas de cultivo, nos pousios, nas rotações de culturas e preparação dos solos, nas alfaias agrícolas (mais operativas com a aplicação de peças de ferro), no aproveitamento de diversas forças motrizes, nos diferentes modos de produção, mas verdadeiramente a revolução agrícola correu a par com a revolução industrial nos séculos XVIII e XIX. A indústria modernizou a agricultura com a maquinaria agrícola, com a aplicação dos químicos, dos adubos aos pesticidas, com a melhoria dos transportes, fomentando o estímulo do mercado. 